\title{
A social work study to measure the effect of unemployment
}

\author{
Faezeh Taghipour $^{\mathrm{a}}$, Gholamreza Tajbakhsh ${ }^{\mathrm{b}}$, Allahyar Arabmomeni ${ }^{\mathrm{c}}$ and Mohammad Reza Iravani ${ }^{\mathrm{d}^{*}}$
}

\begin{abstract}
${ }^{a}$ Assistant Professor, Department of Cultural Management Khorasgan (Isfahan) Branch, Islamic Azad University, Isfahan, Iran
${ }^{b}$ Assistant Professor of Sociology Grand Ayatollah Boroujerd, Iran

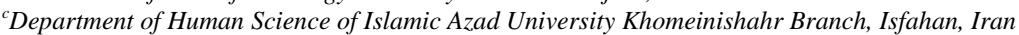

${ }^{d}$ Assistant Professor , Department of Social Work, Islamic Azad University of Khomeinishahr, Khomeinishahr Branch, Daneshjou Blvd, Iran

ARTICLEINFO ABSTRACT

Article history:

Received March 25, 2012

Received in revised format

25 September 2012

Accepted 4 October 2012

Available online

October 72012

Keywords:

Unemployment

Drug addiction

Rubbery

Unemployment is believed as one of most important issues in today's economy around the world. The recent economic turmoil in European countries, for instance, has created some troubles such as increase in rate of depression, divorce, etc. In this paper, we present a social study work in one of regions of Iran. The proposed study of this paper designs and distributes a questionnaire among 80 experts who live in the region and tries to understand whether there is a correlation between unemployment and rubbery, immigration, drug addiction and non-value jobs. The survey uses Pearson correlation to test four hypotheses and the results indicate that although there is no strong correlation between unemployment and rubbery and immigration but there is a strong evidence to believe that unemployment can increase drug addiction and non-value added jobs.
\end{abstract}

\section{Introduction}

These days, there is growing concerns among different North American, European and other countries about the consequences of the effects of unemployment in their societies. In fact, when people lose their jobs, they may face many challenges such as family conflict, drug addiction, unwanted immigration, etc. During the past few years, there have been interest in learning more about the effect of unemployment on different social factors. Congregado et al. (2011) explained that Spain has been destroying more jobs than any other European country in recent years and in 2012 the rate reached to about $24 \%$. The exponential growth of the Spanish unemployment rate was the by-product of falling employment rates.

Lundin et al. (2012) discussed on various studies on a higher risk of suicide among the unemployed, where some individuals may be more prone to both unemployment and suicide because of healthrelated factor. In such case, suicide among the unemployed could be a consequence of health-related

* Corresponding author. Tel: +989130758065

E-mail addresses: iravani@iaukhsh.ac.ir (M.R. Iravani) 
selection. Lundin et al. (2012) investigated the relationship between unemployment and suicide, and the importance of other sickness absence to this relationship. According to their survey, higher levels of sickness absence were associated with an increased risk of subsequent unemployment. The higher prevalence of sickness absence among the unemployed attenuated the relationship between unemployment and suicide in both women and men.

Noh (2009) performed an investigation on whether the relationship between unemployment rates and suicide rates vary based on the level of real per capita gross domestic product (GDP). They used the cross-country panel fixed influences model to exclude cross-sectional variations but exploit timeseries ones. They reported that higher income was related to higher suicide rates. In other words, their results showed that the implied impact of unemployment on suicide rates was positive for countries with higher income. According to their survey, for countries with lower-income levels, there was a negative impact of unemployment on suicides.

Chang et al. (2010), in another survey reported that an increase in unemployment was associated with an increase in male suicide rates, but evidence for an association in females was reported to be limited. In the model controlling for changes in GDP per capita, GDP growth, divorce and female labor force participation, for each 1\% rise in unemployment, male suicide rates elevated by 3.1 (95\% confidence interval 1.4-4.8) per 100,000. Kuroki (2010) performed another investigation between suicide and unemployment in Japan. The study indicated that unemployment was substantially associated with male suicide rates but the results did not make any clear judgment on female suicide rates.

Jean and Jiménez (2011) evaluated the consequences of immigration for natives' unemployment in OECD countries and studied the impact played by product and labor market policies in the adjustment of the economy to immigration inflows over the period 1984-2003. They reported that immigration could have a temporary effect on natives' unemployment, depending upon the policy framework. In other words, a temporary increase in unemployment were observed in a context of stringent anticompetitive product market regulation, or of high replacement rates of unemployment benefits.

Zunzunegui et al. (2006) investigated the relationship between community unemployment and the physical and mental health of immigrants compared with non-immigrants in city of Montreal, Canada. They looked to see whether high unemployment in the community could create more negative impacts on the health of immigrants than on non-immigrants. They reported that among neighbourhoods, variations in the three health outcomes were weak, and differences in health were not related to differences in community unemployment. The relationship between community unemployment and health was different based on immigration status. At the individual level, immigrants did not differ from non-immigrants with respect to the three health indicators, except that second-generation males were a bit heavier. Nevertheless, when living in areas of high unemployment, immigrants had poor physical and mental health compared with non-immigrants. Among first-generation immigrants, community unemployment was related to psychological distress but among second-generation immigrants, the likelihood of obesity and poor self-rated health increased substantially for those who lived in areas with high unemployment.

Fuller (2011) investigated on rich representative panel data from Statistics Canada's Survey of Labor and Income Dynamics (SLID) to evaluate the outcomes and dynamics of temporary employment. Based on the survey, they provided a more pessimistic picture of overall temporary job outcomes than prior research but recommended that the dynamics of temporary work did not magnify inequalities of gender and immigration status. 
In this paper, we present an empirical study to investigate the relationship between unemployment rate and four social factors including rubbery, immigration, drug addiction and non-value jobs. The organization of this paper first presents the details of our proposed model in section 2 and our findings are given in section 3. The paper ends with concluding remarks to summarize the contribution of the paper.

\section{The proposed model}

The proposed study of this paper tries to find out whether there is an association between unemployment rate and other social factors including rubbery, immigration, drug addiction and nonvalue added jobs. There are four hypothesis with the proposed study of this paper as follows,

1. There is a positive relationship between unemployment and rubbery.

2. There is a positive relationship between unemployment and immigration.

3. There is a positive relationship between unemployment and drug addiction.

4. There is a positive relationship between unemployment and non-value added jobs.

The proposed study of this paper was held on one of small towns in province of Esfahan, Iran called Jarghoyeh Sofla. The city had a population of approximately 16200 people. The proposed study designed a questionnaire consists of 38 questions and distributed among 80 people who were randomly selected in this city. The study used Pearson correlation ratio to test different hypotheses. In this survey, $50 \%$ of the surveyed people were male and $50 \%$ were female and in terms of marital status, $61 \%$ were single and the rest of them were married and finally, $61 \%$ of the surveyed people were between 17 to 27 years old and this indicates that most of these people were relatively young people.

\section{The results}

We have used Pearson correlation ratio to examine whether there is a positive and meaningful relationship between unemployment and other four mentioned factors. Table 1 shows details of our findings.

\section{Table 1}

The results of Pearson correlation test (Level of Significance: 5\%)

\begin{tabular}{lcccc}
\hline Variable & Mean & Median & Variance & Pearson ratio \\
\hline Unemployment & 54.66 & 53.2 & 167.38 & 0.216 \\
Rubbery & 9.01 & 8.3 & 6.46 & 0.724 \\
\hline Unemployment & 54.66 & 53.2 & 167.38 & 0.623 \\
Immigration & 6.21 & 5 & 5.36 & 0.836 \\
\hline Unemployment & 54.66 & 53.2 & 6.31 & 167.38 \\
Drug addiction & 8.2 & 8 & 6.57 & \\
\hline Unemployment & 54.66 & 53.2 & 7.1 & \\
Non-value added jobs & 8.16 & & & \\
\hline
\end{tabular}

As we can observe from the results of Table 1, there is a strong relationship between unemployment from one side and immigration and non-value added jobs from the other side. While there is a relatively high correlation between unemployment and drug addiction, there is no strong relationship between unemployment and rubbery. In other words, one immediate impact of unemployment can be described in creation of non-value added jobs where community cannot benefit. The other major problem is the immigration. People migrate from small towns towards big cities for better job opportunities while some face with much bigger problems such as drug dealers, smugglers, etc. In 
summary, unemployment is unwelcome incident in any societies and could have some bad effects where some of them are irreversible.

\section{Conclusion}

In this paper, we have presented an empirical study to see whether there is a strong relationship between unemployment of some social factors such as rubbery, immigration, drug addiction and nonvalue jobs. The survey has implemented Pearson correlation to examine four hypotheses and the results have indicated that although there is some weak correlation between unemployment and rubbery and immigration but there is a strong evidence to believe that unemployment can increase drug addiction and non-value added jobs.

\section{Acknowledgement}

The authors would like to thank the anonymous referees for the comments on earlier version of this paper.

\section{References}

Chang, S.S., Sterne, J.A.C., Huang, W.-C., Chuang, H.-L., \& Gunnell, D. (2010). Association of secular trends in unemployment with suicide in Taiwan, 1959-2007: A time-series analysis. Public Health, 124(1), 49-54.

Congregado, E., Golpe, A.A., \& van Stel, A. (2011). Exploring the big jump in the Spanish unemployment rate: Evidence on an 'added-worker' effect. Economic Modelling, 28(3), 10991105

Fuller, S. (2011). Up and on or down and out? Gender, immigration and the consequences of temporary employment in Canada. Research in Social Stratification and Mobility, 29(2), 155-180

Kuroki, M. (2010). Suicide and unemployment in Japan: Evidence from municipal level suicide rates and age-specific suicide rates. The Journal of Socio-Economics, 39(6), 683-691.

Jean, S., \& Jiménez, M. (2011). The unemployment impact of immigration in OECD countries. European Journal of Political Economy, 27(2), 241-256

Lundin, A., Lundberg, I., Allebeck, P., \& Hemmingsson, T. (2012). Unemployment and suicide in the Stockholm population: A register-based study on 771,068 men and women. Public Health, 126(5), 371-377.

Noh, Y.H. (2009). Does unemployment increase suicide rates? The OECD panel evidence. Journal of Economic Psychology, 30(4), 575-582.

Zunzunegui, M.V., Forster, M., Gauvin, L., Raynault, M.F., \& Willms, J.D. (2006). Community unemployment and immigrants' health in Montreal. Social Science \& Medicine, 63(2), 485-500. 